\title{
Reducing HIV infection among youth: What can schools do? Key baseline findings from Mexico, South Africa, and Thailand
}

Holley Stewart

Ann P. McCauley

Simon Baker

Martha Givaudan

Shegs James

See next page for additional authors

Follow this and additional works at: https://knowledgecommons.popcouncil.org/departments_sbsr-hiv

Part of the Education Commons, and the International Public Health Commons How does access to this work benefit you? Let us know!

\section{Recommended Citation}

Stewart, Holley, Ann P. McCauley, Simon Baker, Martha Givaudan, Shegs James, Iwin Leenen, Susan Pick, Priscilla Reddy, Usasinee Rewthong, Patchara Rumakom, and Dilys Walker. 2001. "Reducing HIV infection among youth: What can schools do? Key baseline findings from Mexico, South Africa, and Thailand," Horizons Report. Washington, DC: Population Council. 


\section{Authors}

Holley Stewart, Ann P. McCauley, Simon Baker, Martha Givaudan, Shegs James, Iwin Leenen, Susan Pick, Priscilla Reddy, Usasinee Rewthong, Patchara Rumakom, and Dilys Walker 


\title{
Hgrizons
}

\section{Reducing HIV Infection Among Youth: What Can Schools Do?}

\author{
Key Baseline Findings from \\ Mexico, South Africa, and Thailand
}

Horizons

ICRW

IMIFAP

MRC

PATH

Population Council 


\section{Reducing HI V I nfection Among Youth: What Can Schools Do? \\ Key Baseline Findings from \\ Mexico, Thailand, and South Africa}

Holley Stewart, Ann McCauley, Simon Baker, Martha Givaudan, Shegs J ames, I win Leenen, Susan Pick, Priscilla Reddy, Usasinee Rewthong, Patchara Rumakom, Dilys Walker 


\title{
Acknowledgments
}

Many individuals contributed to this study and report. The research teams in Mexico, South Africa, and Thailand carried out the research, analyzed the country-specific data, worked cooperatively to compare results, and reviewed the report. Working with them, Holley Stewart combined the three data sets, analyzed the data and wrote the report with Ann McCauley. Scott Geibel guided the data analysis and Sherry Hutchinson prepared the tables for publication. Christina Grabowski, Naomi Rutenberg, Margaret Dadian, and Ellen Weiss reviewed the report.
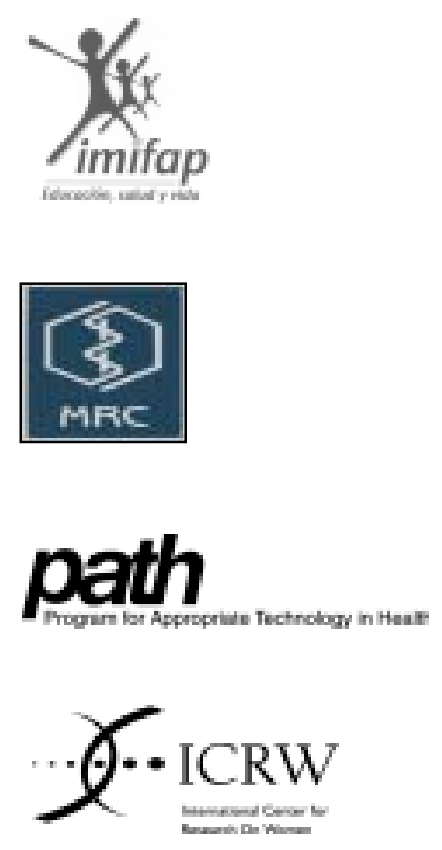

\section{Hgrizons}

Mexico

Susan Pick, Instituto Mexicano de Investigación de Familia y Población (IMIFAP)

Martha Givaudan, IMIFAP

Dilys Walker, Horizons/Population Council

Iwin Leenen, IMIFAP

South Africa

Priscilla Reddy, Medical Research Council (MRC)-Cape Town

Shegs James, MRC - Cape Town, based at the School of Public Health and Family Medicine, University of Natal, Durban

Thailand

Simon Baker, Horizons/Program for Appropriate Technology in Health (PATH) Usasinee Rewthong, PATH

Patchara Rumakom, Horizons/Population Council

Srisuman Sartsara, Horizons/Population Council

Washington, DC, USA

Ann McCauley, Horizons/International Center for Research on Women (ICRW) Holley Stewart, Horizons/Population Council

Scott Geibel, Horizons/Population Council

Sherry Hutchinson, Horizons/Population Council

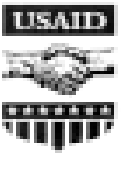

\begin{abstract}
This study was supported by the Horizons Program. Horizons is funded by the U.S. Agency for International Development, under the terms of HRN-A-00-97-00012-00. The opinions expressed herein are those of the authors and do not necessarily reflect the views of the U.S. Agency for International Development.
\end{abstract}

Published in October 2001.

\begin{abstract}
A Population Council
The Population Council is an international, nonprofit, nongovernmental institution that seeks to improve the wellbeing and reproductive health of current and future generations around the world and to help achieve a humane, equitable, and sustainable balance between people and resources. The Council conducts biomedical, social science, and public health research and helps build research capacities in developing countries. Established in 1952, the Council is governed by an international board of trustees. Its New York headquarters supports a global network of regional and country offices.
\end{abstract}

Copyright (C) 2001 The Population Council Inc. 


\section{Table of Contents}

Executive Summary 1

Introduction 3

The Horizons Studies 5

Study goal $\quad 5$

HIV prevalence and degree of public HIV programming in each site 5

$\begin{array}{ll}\text { Study design } & 6\end{array}$

$\begin{array}{ll}\text { Comparison across sites } & 7\end{array}$

Study variables $\quad 8$

Age and sex of the samples $\quad 8$

Key Baseline Findings $\quad 10$

$\begin{array}{ll}\text { A majority of female students have not had penetrative sex } & 10\end{array}$

More boys than girls having first sex at or before 15 years of age 12

$\begin{array}{ll}\text { Students have sex intermittently } & 14\end{array}$

$\begin{array}{ll}\text { Students misjudge peers' level of sexual activity } & 14\end{array}$

Sexually experienced students do not see themselves at higher risk than 16 sexually inexperienced youth

Misperceptions and uneven knowledge about HIV persist 18

Ambivalent feelings about people living with HIV/AIDS (PLHA) 18

Many students are not confident they know how to use condoms correctly 19

$\begin{array}{ll}\text { Conclusions } & 23\end{array}$

$\begin{array}{ll}\text { References } & 25\end{array}$ 


\section{List of Tables and Figures (in order of appearance)}

Table 1 Age means of study cohorts

Figure 1 Current age and ever had sex (Mexico) (all, males, females)

Figure 2 Current age and ever had sex (South Africa) (all, males, females)

Figure 3 Current age and ever had sex (Thailand) (all, males, females)

Table 2 Ever had sex (by sex and country)

Figure 4 Age at first sex among sexually experienced (Mexico)

Figure 5 Age at first sex among sexually experienced (South Africa)

Figure 6 Age at first sex among sexually experienced (Thailand)

Figure 7 Distribution of ever had sex, sex during recall period and perception of peers' sexual activity (All)

Figure 8 Distribution of ever had sex, sex during recall period and perception of peers' sexual activity (Males)

Figure 9 Distribution of ever had sex, sex during recall period and perception of peers' sexual activity (Females)

Figure 10 Risk perception by sexual activity (Mexico)

Figure 11 Risk perception by sexual activity (South Africa)

Figure 12 Risk perception by sexual activity (Thailand)

Figure 13 HIV-related knowledge

Figure 14 Knowledge/attitudes about PLHA

Figure 15 Confidence to access and correctly use a condom (All)

Figure 16 Confidence to access and correctly use a condom (Males)

Figure 17 Confidence to access and correctly use a condom (Females)

Figure 18 Condom Use ( $\mathrm{n}=$ sexually experienced who had sex during recall period (Mexico, Thailand)

Figure 19 Condom Use ( $\mathrm{n}=$ sexually experienced who had sex during recall period) (South Africa) 


\section{Executive Summary}

Although many program planners see schools as a convenient location for HIV prevention programs, there is controversy about whether school programs can ever be strong enough to go beyond improving knowledge and attitudes to increasing the adoption of safe sexual behaviors. Evaluations of school programs in Mexico, South Africa, and Thailand focus on this question: Can school HIV programs change behavior? In each country, local organizations have worked with educators on teacher training and course design to ensure high-quality school interventions. Researchers surveyed students' knowledge, attitudes, norms, and reported behavior before the intervention, immediately after the intervention, and again several months later to measure retention of program effects. In all three sites comparable control groups are being compared to the intervention group. The mean age and age ranges for the three study groups are: 16 years and age 13 to 23 for the Mexican study group; 15 years and 8 months and ages 12 to 21 for the South African study group; and 20 years and ages 17 to 31 for the Thai study group.

The following report is a summary of key baseline findings from these studies. The studies found that:

- A majority of girls have not had penetrative sex. Most girls in all three countries reported that they had never had sexual intercourse. In Mexico, a majority of the boys were also not sexually experienced.

- More boys than girls are having first sex at or before 15 years of age. In each country a sizeable proportion of the students reported having had penetrative sex for the first time when they were younger than fifteen years old. Boys were more likely to report early sex than girls.

- Students have sex intermittently. More students in all three sites reported ever having had sex than reported having had sex than reported having had sex during the recall period prior to baseline data collection (4 to 6 months).

- Students misjudge peers' level of sexual activity. In Thailand students thought that more of their classmates were sexually active than were actually sexually experienced. However the opposite was true for the other countries.

- Sexually experienced students do not always see themselves at higher risk than sexually inexperienced youth. In all three countries sexually experienced and inexperienced students saw themselves at the same level of risk. In South Africa about 20 percent of all respondents did not know whether they were at risk. 


\section{Hgrizons}

- Students have misperceptions and uneven knowledge about HIV. Although the great majority of students knew something about HIV, they were unaware or mistaken about other important information concerning HIV prevention.

- Students have ambivalent feelings about people living with HIV. Students agreed that HIVpositive students should continue to go to school, but they were unsure about whether close contact with an HIV-positive person was always safe.

- Many students are not confident that they know how to use a condom correctly. Although many students said that they knew how to get a condom, a large proportion, especially girls, reported that they did not know how to use one.

- Many sexually active students do not use condoms. Even among students who were confident that they knew how to use a condom, many who were sexually active during the recall period prior to baseline data collection did not report using one at last sex. 


\section{Introduction}

This research project addresses a central question on HIV programs for youth: Can school programs lead to increased safe behavior among students, or are these programs only able to increase knowledge and positive attitudes about HIV/AIDS? School-based programs for family planning education and HIV prevention have successfully increased students' knowledge and positive attitudes toward reproductive health in many places (Cáceres et al. 1994; Kirby 1997; Pick de Weiss et al. 1990). Moreover, there are several U.S. programs that are associated with reduction of high-risk behaviors (Kirby 1999). There are, however, few examples of school programs in developing countries that are associated with increases in reported behaviors that protect youth from HIV infection (Fitzgerald et al. 1999; Stanton et al. 1998).

Recent reviews of school-based efforts that have led to adoption of safe sex practices found that they share the following characteristics (Kirby 1999; Grunseit 1997):

- A clear focus on reducing one or more sexual behaviors (e.g., unprotected intercourse, multiple partners) that lead to unintended pregnancy or HIV/STD infection.

- Use of behavioral goals, teaching methods, and materials that are appropriate to the age, sexual experience, and culture of the students.

- A basis in one of the theoretical approaches that have been demonstrated to be effective in influencing other health-related risky behaviors (e.g., social learning theory, stages of change theory).

- Duration sufficient to complete important activities adequately.

- Use of a variety of teaching methods designed to involve participants and have them personalize the information.

- Provision of basic, accurate information about the risks of unprotected intercourse and methods of avoiding unprotected intercourse.

- Activities that address the social pressures on sexual behaviors and peer influences during the course.

- Opportunities for modeling and practice of communication, negotiation, and refusal skills.

- Selection and training of teachers or peers who believe in the program.

As noted above, two of the key program features that have led to behavior change are the use of interactive teaching methods and the provision of explicit information about sexual matters. These are particularly difficult aspects of the program to implement in many places, including most developing countries, where they are not now the norm. The interactive teaching methods require the teacher to avoid the usual didactic presentation of material and to encourage students to actively participate in discussions, role plays, and similar activities. Providing explicit details about matters such as contraception, sexually transmitted infections, and condom use requires that the teachers feel confident talking about these sensitive topics in the classroom.

Finding the strengths and limitations of school programs has consequences for how HIV resources are allocated. Schools seem an obvious location for HIV programs because they reach large numbers of young people. If such programs can have an impact on behavior, it may be worth the expense of adequately training teachers to use the interactive methods that bring about behavior 


\section{Hgrizons}

change. If high quality, school-based programs cannot have an impact on behavior, programs can train teachers to reach the easier goal of increasing knowledge and improving attitudes about HIV/AIDS. This kind of training is less expensive and easier to achieve than training teachers to teach an intensive, interactive behavior change curricula. When planners make the decision to focus school programs on knowledge and attitudes only, they may free up resources for other kinds of programming.

The following report on the baseline data from three countries-Mexico, Thailand, and South Africa-provides information on the HIV-prevention needs school-based youth, and which young people are at greatest risk. We focus on select key variables including HIV knowledge, attitudes toward people living with HIV/AIDS, confidence in acquiring and using condoms, and reported sexual behavior. This information, and other data obtained from the studies, has helped shape the school-based interventions by informing teachers about student needs. It can also be helpful to others planning HIV prevention programs for youth in similar settings. 


\section{The Horizons Studies}

\section{Study Goal}

The Horizons Program is supporting studies in Mexico, South Africa, and Thailand that are designed to help define the role of school-based programs in HIV prevention in order to provide useful information for educational decision-makers in each country. To meet this goal, Horizons sought to study programs that (1) meet all, or almost all, of the characteristics of effective programs listed above, and (2) are part of a plan to institutionalize the school-based HIV/AIDS program at significant scale; that is, at the national or regional level. Fulfilling this last requirement ensures that program experience will have impact that is broader than the pilot program.

\section{HIV Prevalence and Degree of Public HIV Programming in Each Site}

At the end of 1999, the estimated adult HIV prevalence in the three countries varied greatly: less than one percent in Mexico, twenty percent in South Africa, and a little more than two percent in Thailand (UNAIDS 2000). Among young people ages 15 to 24 in South Africa and Thailand, the estimated HIV prevalence was greater for females than for males the same age whereas the opposite was true for Mexico (UNAIDS 2000).

Although Mexico has had HIV/AIDS programs since the early 1980s, only recently has there been a more unified national response. The National AIDS Council of Mexico has put together an overall program against AIDS with participation of different groups and associations (SSA 1999). School-based programs are now being developed and tested as part of that effort.

In South Africa, the school program is one of many HIV prevention and care programs run by the public sector and non-governmental organizations (NGOs). In KwaZulu Natal, where this research is being carried out, there have been large media campaigns and other programs that address HIV infection and the importance of using condoms for prevention. The epidemic in KwaZulu Natal is generalized and is not restricted to certain population groups or geographic areas. A recent KwaZulu Natal voluntary survey of university students, while not fully representative, found infection rates of 26 percent in women and 12 percent in men, aged 20 to 24 (Abt Associates 2000).

The Thai government launched a campaign in 1991 to promote 100 percent condom use in brothels and to reduce unsafe sex practices in the general population. The campaign succeeded in modifying behaviors between clients and sex workers and in reducing the number of commercial sex encounters. Condom use, however, with non-commercial partners has remained inconsistent (Havanon 1996). The challenge for Thailand is to increase the trend in uptake of safe sex practices in non-commercial sex. Introducing an intervention into schools and universities is part of the country's new programming efforts. 


\section{Study Design}

Researchers are collecting qualitative and quantitative data from male and female students at four secondary schools in Mexico, 22 secondary schools in South Africa, and six colleges in central Thailand. In each case half of the schools are receiving the intervention and half are serving as controls. Local school policies and academic calendars determined the duration of the life skills course, the grade level of the students who participated in the intervention, the timing of the intervention, as well as the timing of the pre- and post intervention surveys, and follow-up surveys intended to measure the duration of any program effect.

In Mexico and Thailand researchers used a quasi-experimental research design and in South Africa the researchers used an experimental design. In each site researchers calculated the sample size needed to test the hypothesis that a higher proportion of students who participate in a fact-based, interactive curriculum will adopt and/or maintain safe behaviors such as condom use, than comparable students who do not participate in the course. The required sample size for each site was estimated on the basis of the expected differences of proportions using condoms among the control and the experimental groups after the intervention. In each site researchers adjusted the sample size based on past studies of adolescent sexual activity to try to insure that there would be enough sexually experienced students to measure changes in condom use. In addition they adjusted to accommodate for students who dropped out or refused to participate in the study. Because school intervention effects on knowledge and attitudes are always greater than the effects on practice, the researchers expect that the sample sizes will suffice to test hypotheses on knowledge and attitudes as well.

The Mexican and South African students filled out questionnaires manually while the Thai study had students complete an audio computer-assisted self-interview questionnaire (ACASI). There is evidence to suggest that the ACASI technology may facilitate more accurate reporting by students who are reluctant to report sexual behaviors that are controversial, and even illegal (Turner et al. 1998).

IMIFAP, a non-governmental organization that specializes in adolescent reproductive health, is carrying out the study in Mexico. It administered the teacher training for school faculty members who taught the course in Department of Education schools. IMIFAP chose to work in four urban schools in central Mexico where they had an on-going collaborative relationship. Researchers surveyed all 10th grade students in the two implementation schools and all 10th grade students in the two control schools. The same group of students was surveyed before the intervention, immediately after the intervention, and then at five and ten months after the intervention to measure how long any program effect might last.

In South Africa, the Departments of Education, Health, and Social Welfare designed and carried out the intervention in KwaZulu Natal. In close collaboration with these governmental departments, the MRC is implementing an evaluation of the impact of the course. The researchers chose eleven schools where the life skills course was being introduced and eleven comparable schools that were not yet receiving the program. About fifty students from each school were randomly chosen to participate in the study. The Department of Education curriculum provides 
time for teaching a life skills course in the ninth grade and so all students are in that grade level. The same students in control and intervention schools are being surveyed before and after the intervention and then five months after the end of the course.

In Thailand, the Department of Education introduced a pilot life skills program in the schools in collaboration with PATH and the Horizons Program. Six colleges in central Thailand are participating in the study, with three serving as intervention schools and three as controls. These same students were interviewed before and after the intervention and then four months later.

To further assess the value of school programs, the Horizon studies are also looking at another aspect of these programs-how much the programs cost. Researchers have developed a method for recording program costs in all three countries. This data will enable program planners to see whether these courses are cost effective in comparison to other types of HIV programming for youth.

\section{Comparison Across Sites}

The studies have many similarities and also many differences that will affect the ability to draw broad conclusions.

\section{Similarities}

- All sites implemented a new interactive HIV prevention education curriculum for adolescents.

- All studies evaluated the teacher-training component of the intervention.

- All studies used self-administered, pre- and post intervention questionnaires with students. About 80 percent of the questions were identical in all three sites.

- Each study was carried out with students who are at the age where they are becoming sexually active.

- Each study used a curriculum that has all or most of the components that UNAIDS lists as characteristics of successful HIV prevention school curricula.

- Each curriculum was designed locally by a group of experts who ensured that the course would be culturally appropriate.

\section{Differences}

- Each study had its own independent timeline.

- The studies are being conducted with different age groups and different school levels and settings.

- Each site developed its own curriculum and teacher training model. 


\section{Study Variables}

\section{Variables that measure the impact of the life skills program}

The main intent of the project was to measure the variables that would indicate program impact on male and female students. These variables included:

- Knowledge of HIV and reproductive health issues.

- Attitudes towards people living with HIV.

- Attitudes towards safe sex behaviors.

- Confidence in negotiating safe sex.

- Sexual activity and condom use.

\section{Factors associated with sexual activity}

In addition, the studies include variables that will allow program planners to look at the program effect on the following factors that past research has shown to influence youth's sexual debut, level of sexual activity, and risk behavior (Alan Guttmacher Institute 1994):

- Age-the older an adolescent is the more likely he or she is to have had sex.

- Sex-adolescent males are more likely to have early sex than are females.

- Having a boyfriend or girlfriend - youth with a partner are more likely to be sexually active.

- Influence of parents and friends.

- Cultural norms including gender norms.

- Living arrangements - living at home is associated with a lower likelihood of having sex at an early age.

- Engaging in other high risk behavior such as drinking, smoking, and using drugs.

- Family income-low-income teenagers are more likely than adolescents from wealthier families to be sexually experienced.

The three school-based studies collected information on the first seven factors on the list. For the last item, family income, the characteristics of the school population as a whole are being used as a proxy.

\section{Age and Sex of the Samples}

Half of the Mexican students $(2,064)$ surveyed, were male $(1,021)$ and half were female $(1,037)$ (six students did not indicate their sex). The ages of the students ranged from 13 to 23, with 92 percent between the ages of 15 and 17 .

Of the 1,141 South African students surveyed, 48 percent (545) were male and 51 percent (584) were female (12 students did not indicate their sex). Ages ranged from 12 to 21, with 50 percent older than 16 years. Fifty percent of the South African cohort was older than the typical ages of 14 to 15 years old for ninth grade. This wide age range corresponds with a marked age for grade 
discordance (75 percent were older than grade age range) reported by another South African study (Stewart and Harrison 2000).

Sixty-four percent of the 2,499 Thai students interviewed, were female $(1,596)$ and 36 percent were male (900) (three students did not indicate their sex). The ages of the students ranged from 17 to 31 , with 94 percent of students who reported an age of 21 or less. There was only one student aged 17 and 38 who were 18.

The description of the survey populations includes the younger and older outliers because their inclusion did not substantially alter the mean or median age of the cohorts. The mean and median ages of the Mexican youth were 16 years and 15 years, 10 months. The mean and median ages of the South African students were 15 years, 8 months and 16 years. The mean and median ages of the Thai students were both 20 years.

\begin{tabular}{|c|c|c|c|c|c|c|}
\hline $\begin{array}{l}\text { Study } \\
\text { country }\end{array}$ & Mean & \pm S.D. & Median & $\mathbf{N}$ & Minimum & Maximum \\
\hline Mexico & 16 years & 11 months & $\begin{array}{l}15 \text { years } \\
10 \text { months }\end{array}$ & 2,037 & $\begin{array}{l}13 \text { years } \\
5 \text { months }\end{array}$ & $\begin{array}{l}23 \text { years } \\
4 \text { months }\end{array}$ \\
\hline $\begin{array}{l}\text { South } \\
\text { Africa }\end{array}$ & $\begin{array}{l}15 \text { years } \\
8 \text { months }\end{array}$ & 18 months & 16 years & 1,095 & 12 years & 21 years \\
\hline Thailand & 20 years & 12 months & 20 years & 2,442 & 17 years & 31 years \\
\hline
\end{tabular}

*The 27 Mexican, 46 South African, and 57 Thai respondents who did not report age were excluded from this analysis. 


\section{Key Baseline Findings}

\section{A majority of female students have not had penetrative sex.}

For purposes of this report, the term "sexually experienced" means that one has had penetrative sex at least one time and "sexually active" means that the respondent reported having penetrative sex during the recall period.

Researchers employed culturally acceptable questions as to whether the students ever had sexual intercourse. In Mexico, students were asked at what age they had their first vaginal, oral or anal penetrative sex and, if they gave an age, they were coded as ever having sex. In South Africa, this question was posed differently_-students were asked if they had had sex in the last six months and then at what age they had had first sex. If they gave an age of sexual debut, they were coded as having had sex. In Thailand, students were asked if they had ever had sex of any type, vaginal, oral or anal and, if so, at what age did they have their first penetrative sex.

As expected there was a statistically significant association between age of the students and whether they had had sex: each additional year increased the likelihood that the student experienced sex (Figures 1 to 3 ). In all three sites more boys than girls were sexually experienced (Table 2 and Figures 1 to 3 ).

In all three surveys the majority of the female students have never had sex (Table 2 and Figures 1, 2, and 3). In Mexico and Thailand, the data show that the older female students have not necessarily experienced sex. It may be that in-school females are less likely than out-of-school females to be sexually experienced.

Table 2 Ever had sex (by sex and country)

\begin{tabular}{llll}
\hline & Males \% (n) & Females \% (n) & Chi $^{2} \mathbf{p}$ value \\
\hline Mexico & $25(248 / 982)$ & $7(71 / 1,029)$ & .000 \\
South Africa & $66(356 / 543)$ & $37(218 / 583)$ & .000 \\
Thailand & $61(534 / 878)$ & $29(459 / 1,576)$ & .000
\end{tabular}


Fiaures 1. 2. and 3 Current Aae and Ever Had Sex (Mexico. South Africa. and Thailand)

All

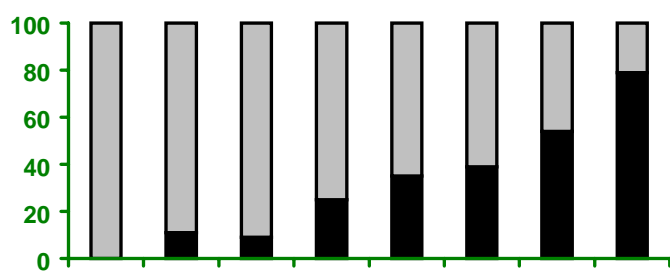

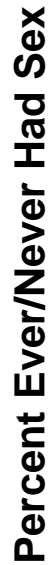
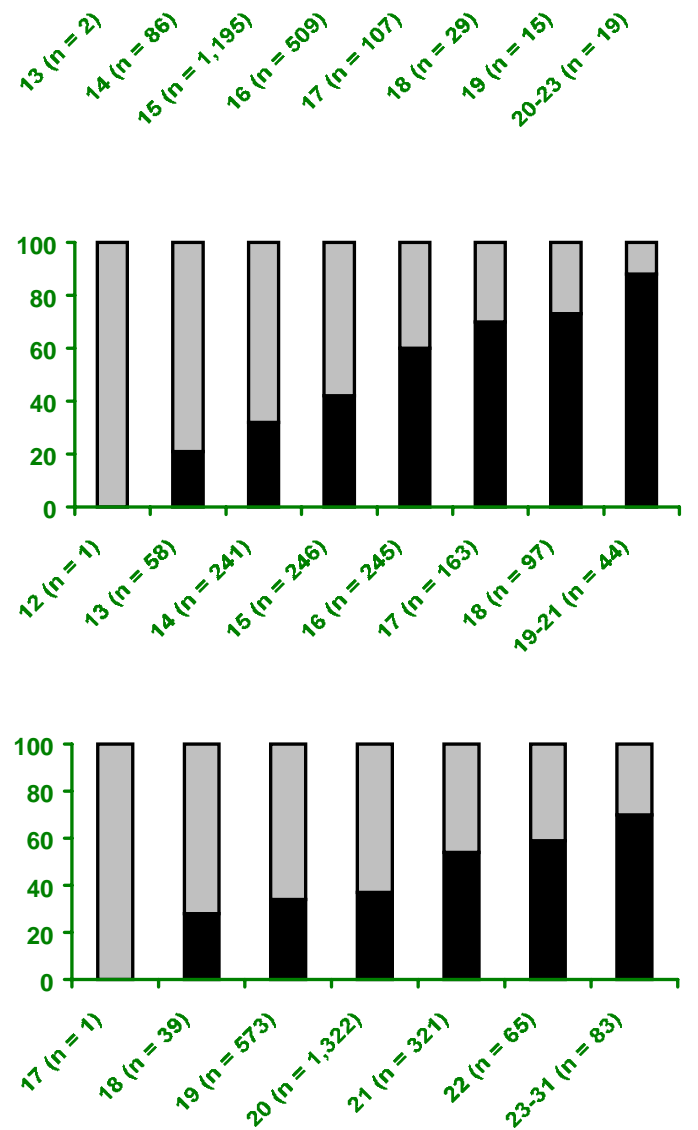

Males
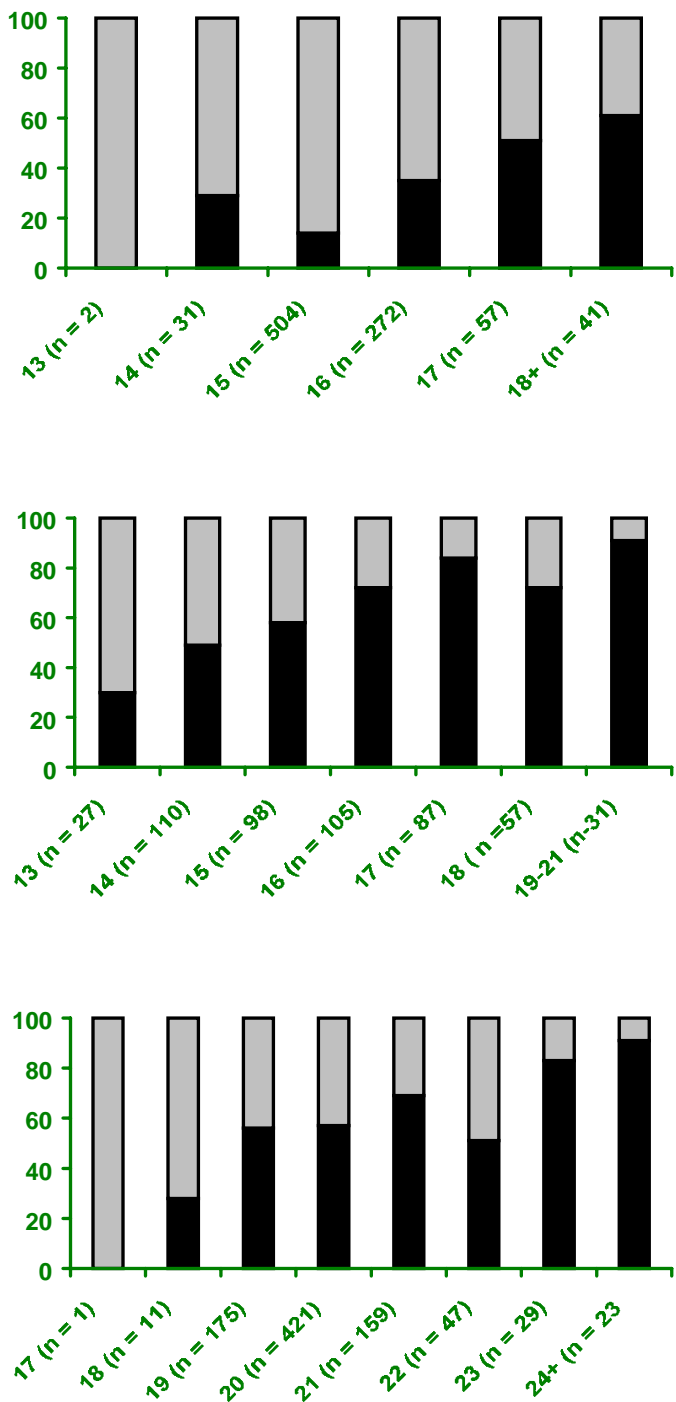

Age ( $\mathrm{n}$ in sample)
Females
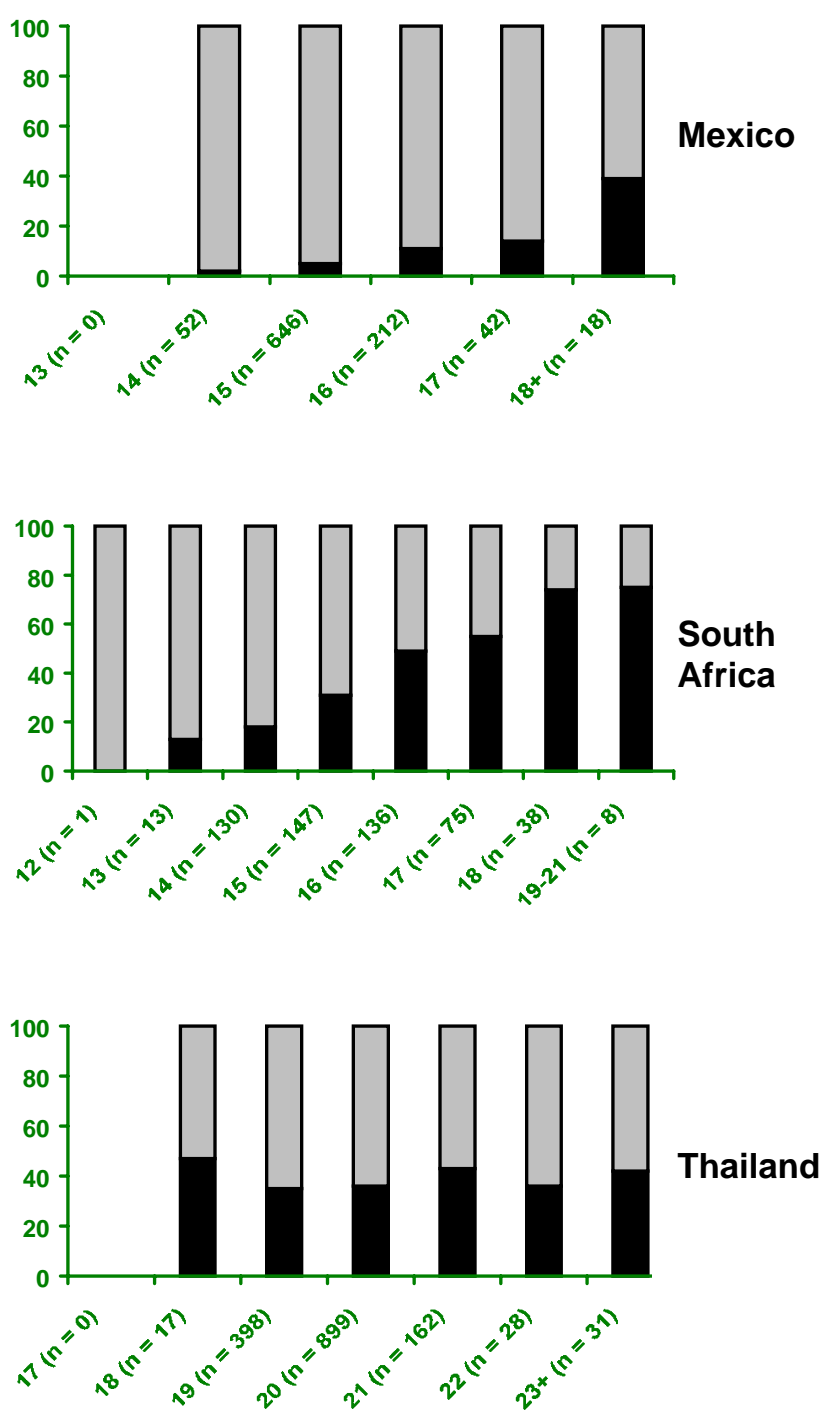

\begin{tabular}{|l|}
\hline$\square \quad \%$ No \\
$\square \quad \%$ Yes
\end{tabular}




\section{More boys than girls are having first sex at or before 15 years of age.}

Students were asked at what age they first had sex. In all three populations (Figures 4, 5, and 6), a sizeable proportion of the sexually experienced students reported their first sex by age 15 (Mexico: 92 percent of males and 91 percent of females; South Africa: 93 percent of males and 63 percent of females; Thailand: 18 percent of males and 7 percent of females). While these numbers are of concern, it is important to remember that the majority of the youth in all studies had not had sex by 15 years, and many older students had not had sex.

It is also important to point out that some students in each country reported sex at age twelve and younger. This suggests the possibility of forced sex which must be addressed by school programs. 
Figures 4, 5, and 6 Age at first sex among sexually experienced

Mexico

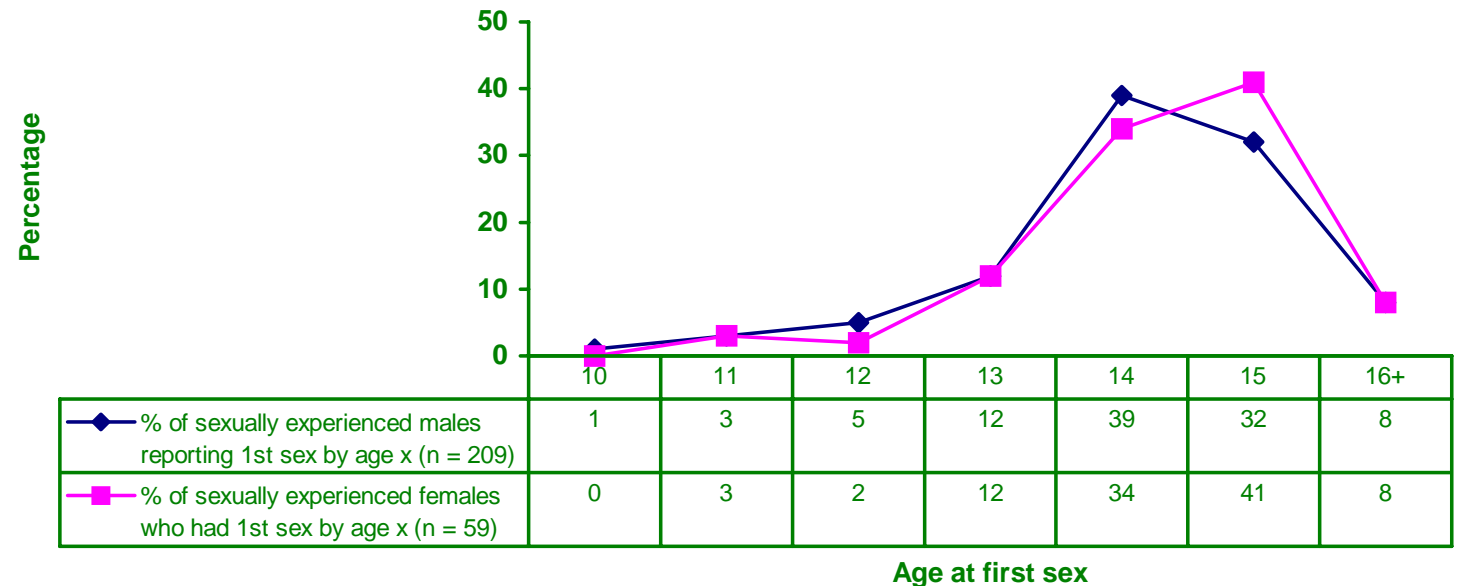

South Africa

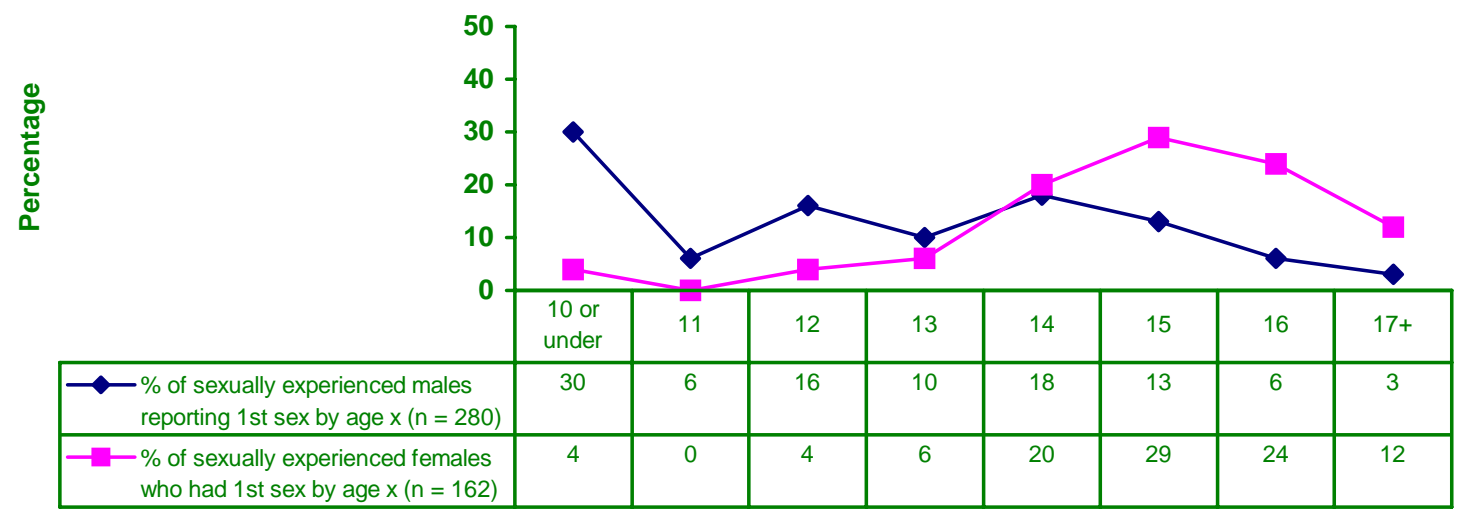

Age at first sex

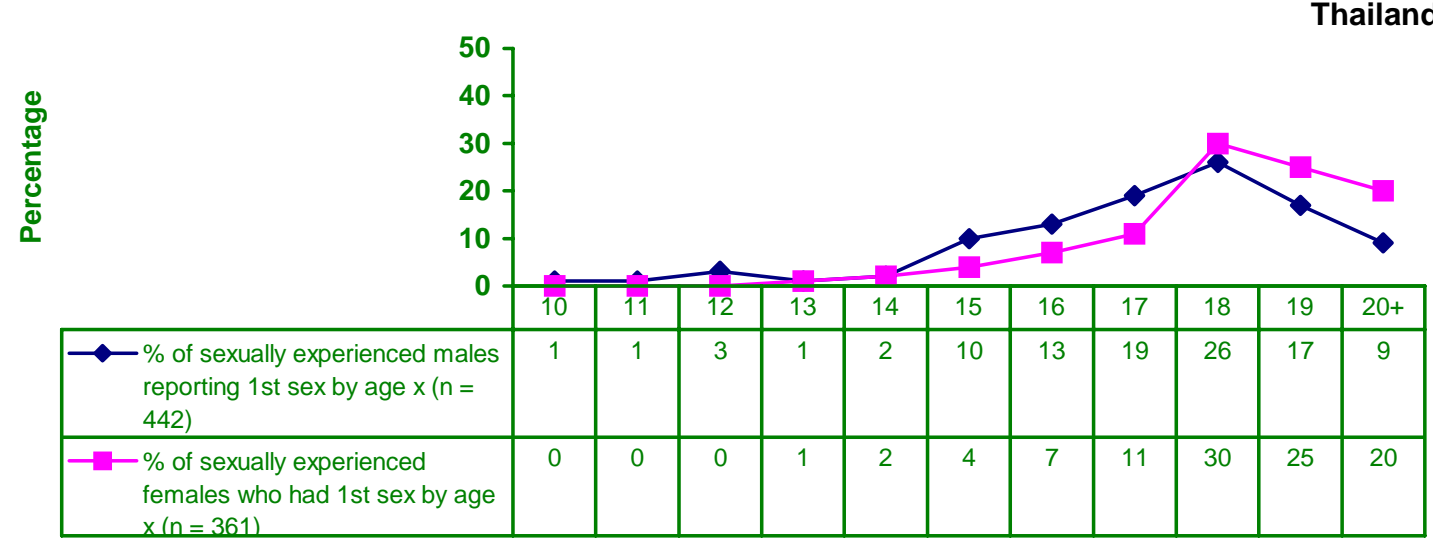

Age at first sex 


\section{Students have sex intermittently.}

The students who had ever had sex were asked to report whether they had been sexually active during a recall period prior to baseline. These recall periods were different among the country study groups. Mexico and South Africa had a recall period of six months, while Thailand's was four months. The figure below shows that although students may have had sexual intercourse, they may not have been sexually active during the recall period prior to baseline data collection (Figures 7 to 9). Approximately two-thirds of the sexually experienced students at the three study sites were sexually active during the recall period

Males were more likely than females to have been sexually active during the recall period except in the Thai study.

\section{Students misjudge peers' level of sexual activity.}

Since many adolescents cite peer pressure as a reason that they become sexually active, the students' perception about whether their classmates are sexually active was compared with the students' reported rates of sexual experience. Students, regardless of sex, underestimated their peers' likelihood to be sexually active in the Mexican and South African studies and overestimated it in the Thailand study (Figures 7, 8, and 9). For the Mexican students, while a total of 16 percent are sexually experienced, only 8 percent of all students believed their peers to be sexually active. For the South African cohort, the response about the students' perception of their peers' sexual activity at 19 percent underestimates the proportion of students who are indeed sexually experienced (51 percent). While 39 percent of the Thai group are sexually experienced, 54 percent of respondents thought that their classmates were having sex. 
Figures 7, 8, 9 Distribution of ever had sex, sex during recall period, and perception of peers' sexual activity

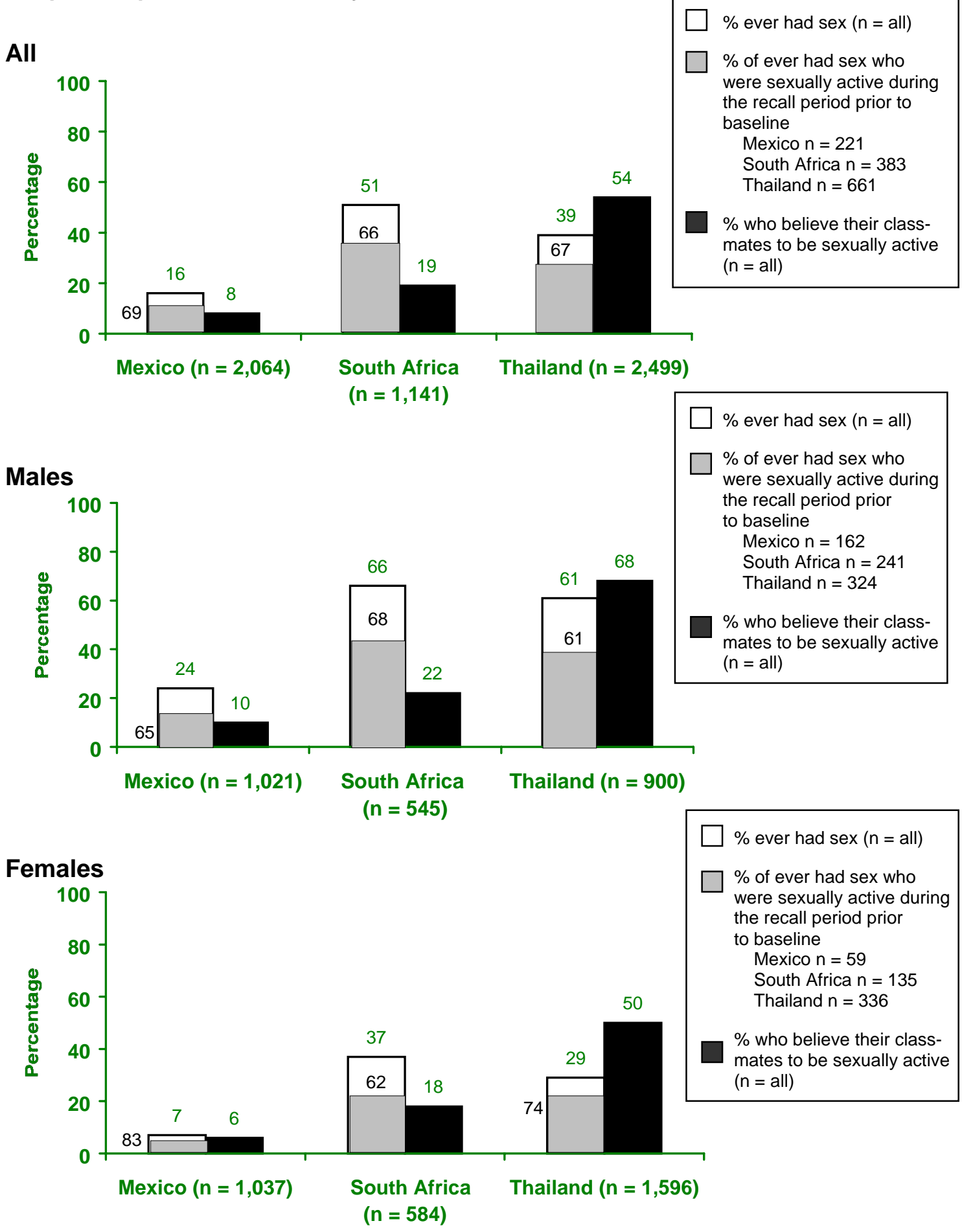




\section{Sexually experienced students do not see themselves at higher risk than sexually inexperienced youth.}

Although sexual activity is the primary risk behavior among these student populations, sexually experienced students in Mexico and Thailand do not rate themselves at higher risk of HIV infection than students who are not sexually experienced (Figures 10,11, and 12). Though their overall HIV knowledge level is high (analysis not shown), 88 percent of the Thai group perceive themselves to be at no to low risk for getting HIV. This perception is true of both the sexually experienced and inexperienced. Among Mexican youth, 41 percent cannot gauge their risk level, no matter whether they are sexually experienced or not. In South Africa as well, the sexually experienced and inexperienced students do not differ much in their assessment of their own risk. Almost equal numbers of both groups see themselves at low, high, and medium risk, and an equal proportion say they do not whether they are at risk.

While risk is probably low for students in Thailand, where adult prevalence is 2 percent, and is certainly low for students in a low prevalence country like Mexico, any student should be aware that abstinent students are at lower risk and that sexual activity involves some risk. In all three country studies, it appears that risk perception may be more affected by a public perception of risk than by an accurate assessment of the students' own behavior. 
Figures 10, 11, and 12 Risk perception by sexual activity
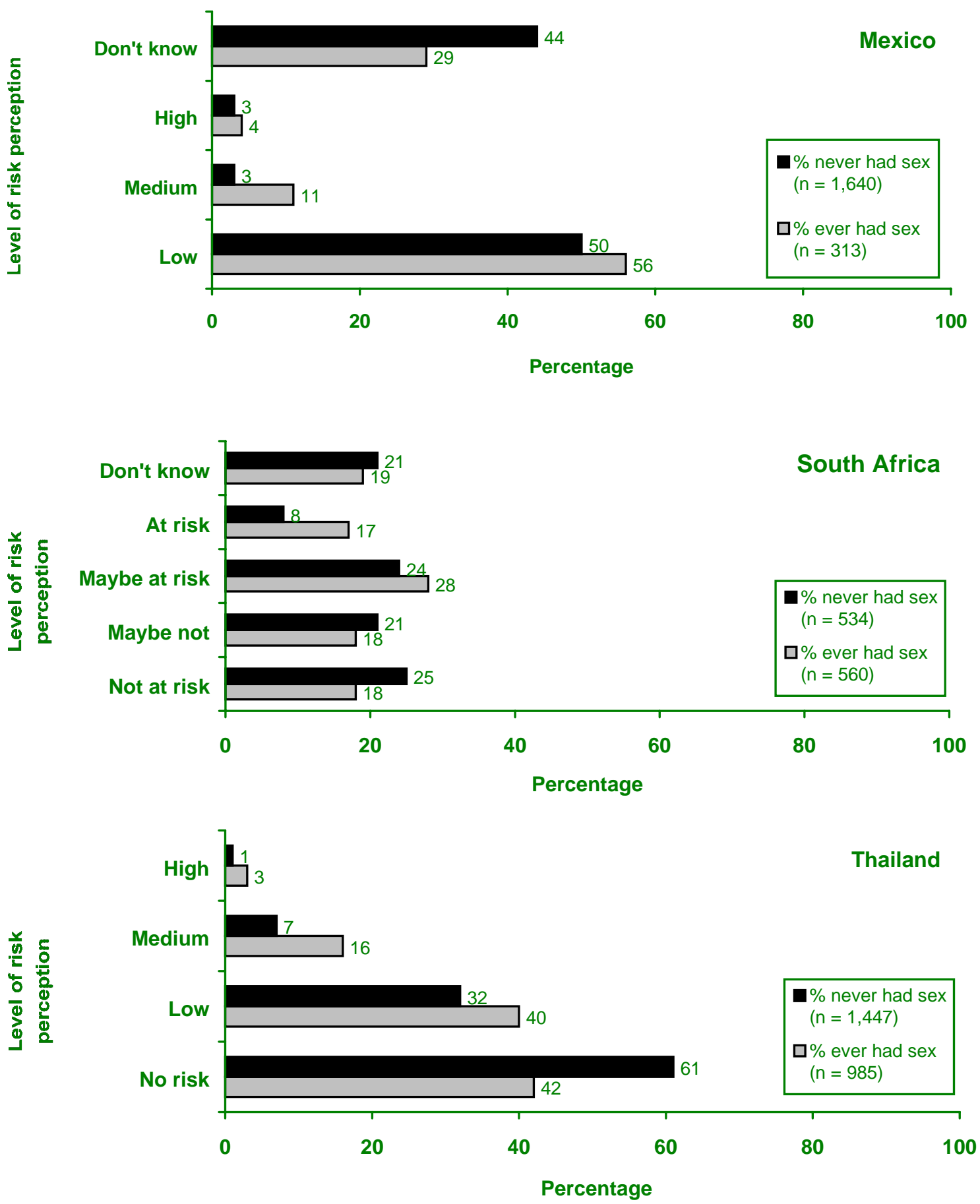


\section{Misperceptions and uneven knowledge about HIV persist.}

Students' HIV knowledge is uneven, no matter whether the country has had a long or short history of the epidemic, low or high HIV prevalence, or a strong national HIV risk-reduction campaign (Figure 13). In Mexico, for example, 94 percent of the students reported that there was something they could do to avoid HIV infection, but fewer students said that an HIV-positive person could look healthy. While 98 percent of the Thai cohort also knew that they could do something to avoid HIV, only 73 percent knew that HIV was not transmittable by sharing food with an HIV-positive person. Almost 20 percent of the South African students were not sure that they could do anything to avoid HIV, and more than a third didn't know whether an HIV-positive person could look healthy. The unevenness suggests that students have a superficial, uneven knowledge of HIV that could prevent them from acting effectively to prevent infection.

\section{Figure 13 HIV-related knowledge}

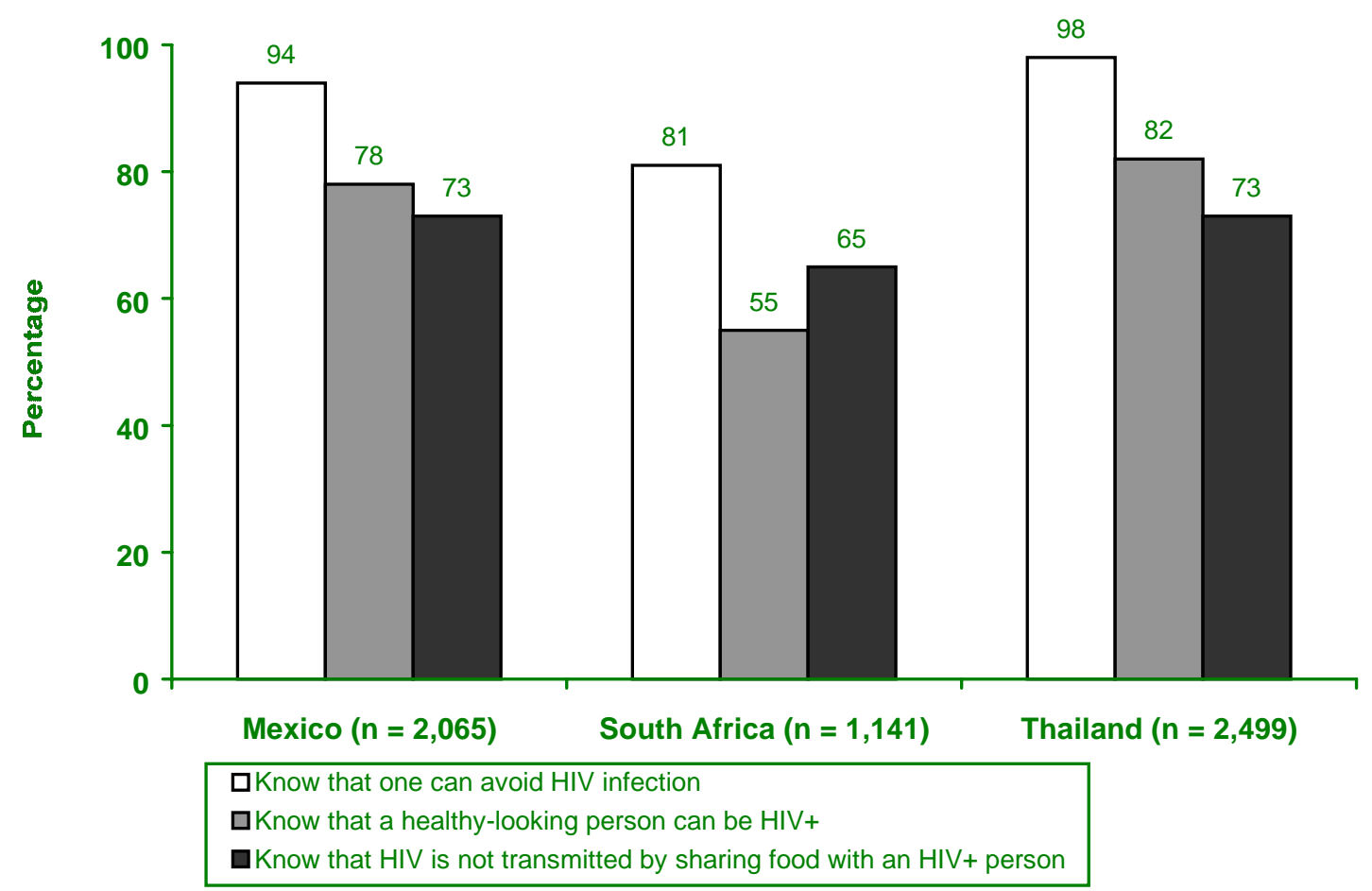

\section{Many youth have ambivalent feelings about people living with HIV/ AI DS (PLHA).}

Although many students agree that HIV-positive students should be permitted to continue in school, more than a quarter of the students in Mexico and South Africa were not sure (Figure 14). Most students knew that one cannot get HIV by sharing food with an HIV-positive person, yet 
many would not buy food from someone with HIV. Popular misconceptions may explain this apparent contradiction. For example, there is widespread belief in Thailand that one should not buy food prepared by an HIV-positive person because blood from a cut finger may have gotten into the food. The interventions need to reduce such misconceptions with accurate information, such as the length of time that the virus can live outside the body.

Figure 14 Knowledge/attitudes about PLHA

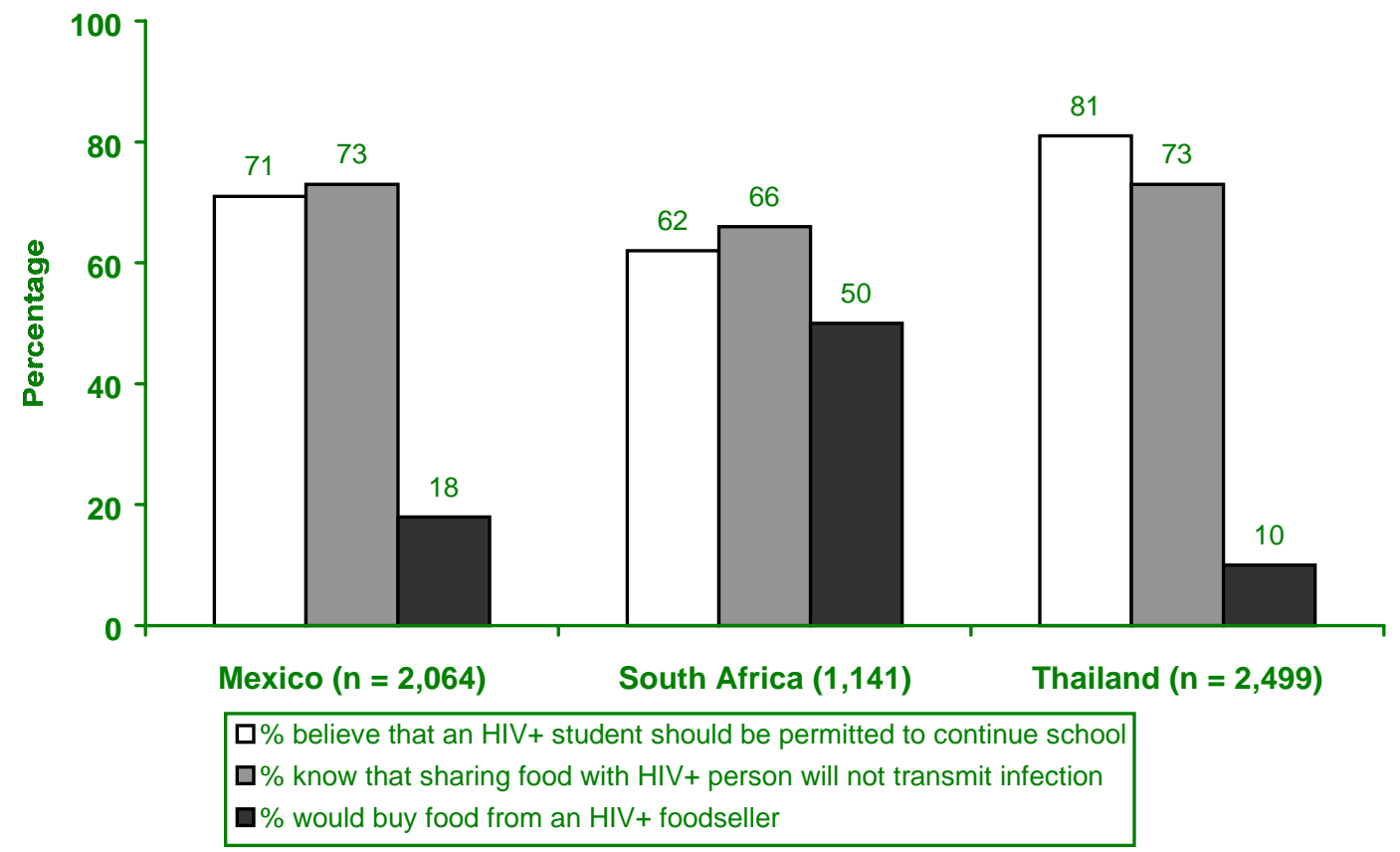

\section{Many students are not confident they know how to use condoms correctly.}

Since condoms are the only technology available that can prevent sexual transmission of HIV and other STIs, it is vital that youth know about them and how to acquire them, and are also confident that they can use them effectively.

Many surveyed students reported that they were confident that they knew how to get a condom if they wanted to, but fewer felt confident that they knew how to use a condom. Less than half the students in Mexico and South Africa were confident that they knew how to use a condom correctly. In Thailand, where the students are older and where there has been a national campaign promoting condom use, 65 percent said they knew how to use a condom correctly (Figure 18). As expected, more males than females in each of the three countries were confident that they could get and use condoms if needed (Figures 18 and 19). 


\section{Hgrizons}

The school courses in all three studies clearly need to increase youth's confidence about using condoms. Nonetheless, these studies' findings show that condom use is fairly high among sexually experienced youth who had had sex during the recall period prior to baseline data collection. In Mexico, of the small group of youth who were sexually active, 61 percent had reported using a condom at last sex, with boys more likely to use condoms than girls (65 percent v. 49 percent) (Figure 18).

Despite Thai students' high rate of confidence in how to procure condoms (81 percent) and in how to use them correctly ( 65 percent), only 27 percent of the students who were sexually active during the recall period reported condom use at last sex (Figures 15 and 18).

In South Africa, a surprising 53 percent of all students who were sexually active during the recall period reported using condoms during every act of intercourse during that period (Figure 19). The South African condom use data are remarkable when compared to the South African 1998 Demographic and Health Survey preliminary report, which reports that while 66 percent of 15- to 19-year-old females use a contraceptive method, only 6 percent use condoms as their method, and, of those, only 20 percent used condoms at last sex (National Department of Health of South Africa 1998). However, other studies have also found a trend of increasing safe sex practices, including condom use among South African youth (Rutenberg et al. 2001; Richter et al. 1995).

Youth reported that they are more concerned about contraception than protection against sexually transmitted infections. Thus, condom use may be affected by access to other forms of contraception. High condom use in Mexico may reflect easier access to condoms versus other forms of birth control, or greater motivation to use them as a form of contraception. Low condom use rates among students in Thailand may be a sign of easier access to and preference for contraceptive pills. 
Figures 15, 16, and 17 Confidence to access and correctly use a condom
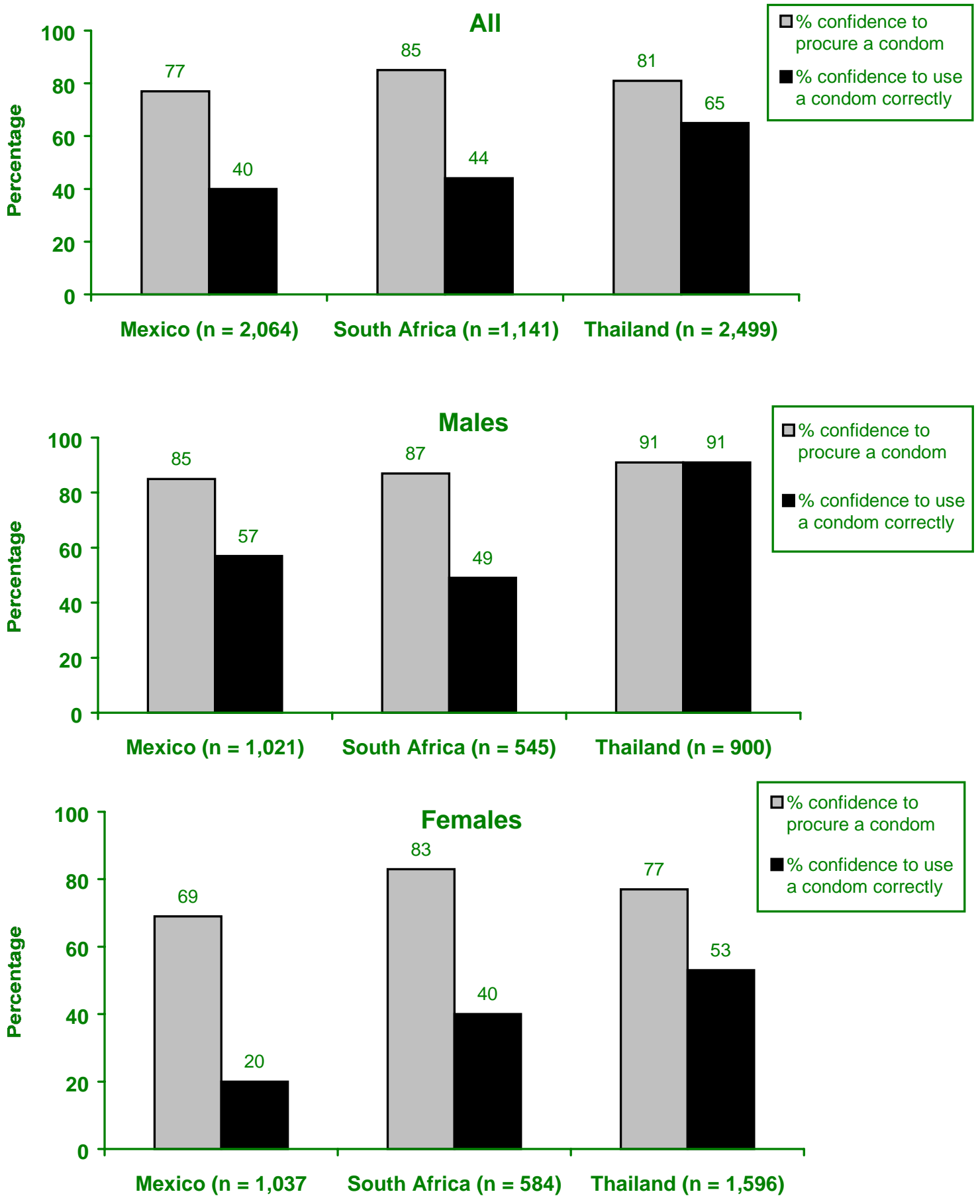
Figure 18 "I used a condom at last sexual encounter."

( $n$ = sexually experienced who had sex during recall period)

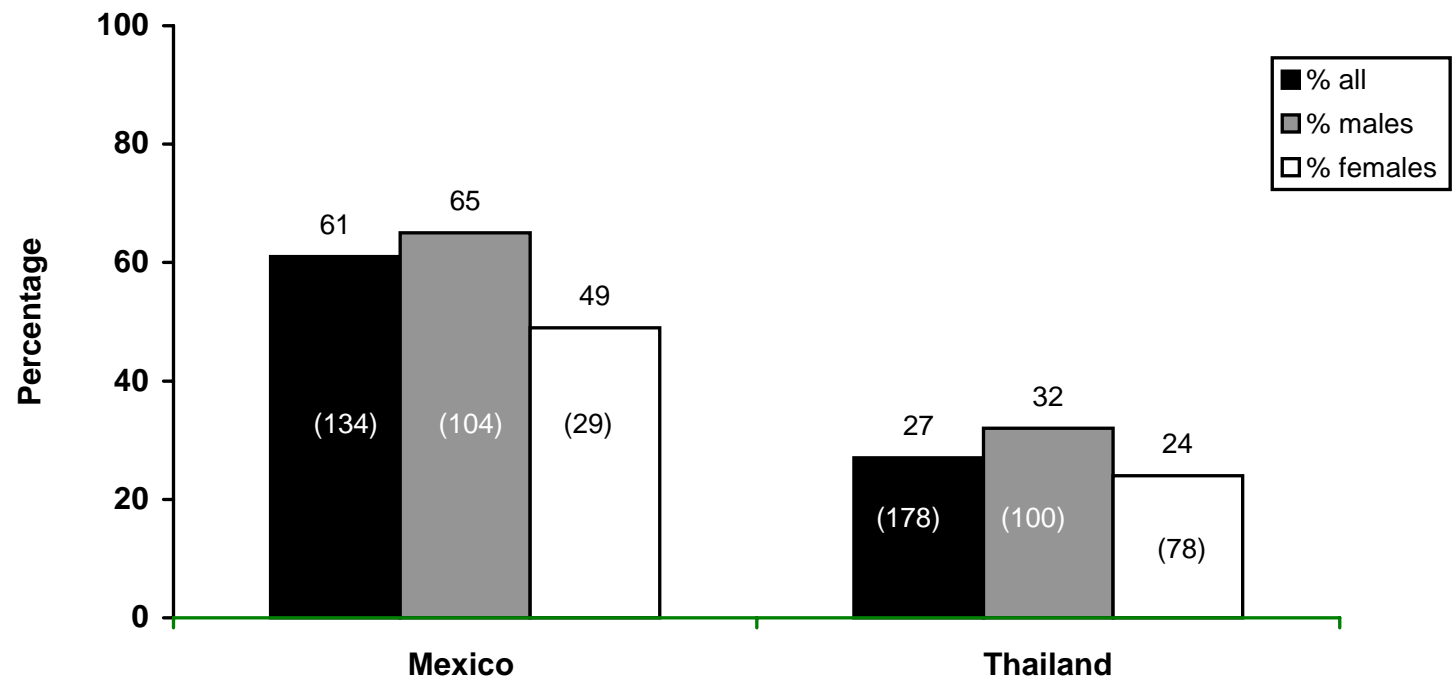

Figure 19 "I used a condom at every sexual encounter."

( $n$ = sexually experienced who had sex during recall period)

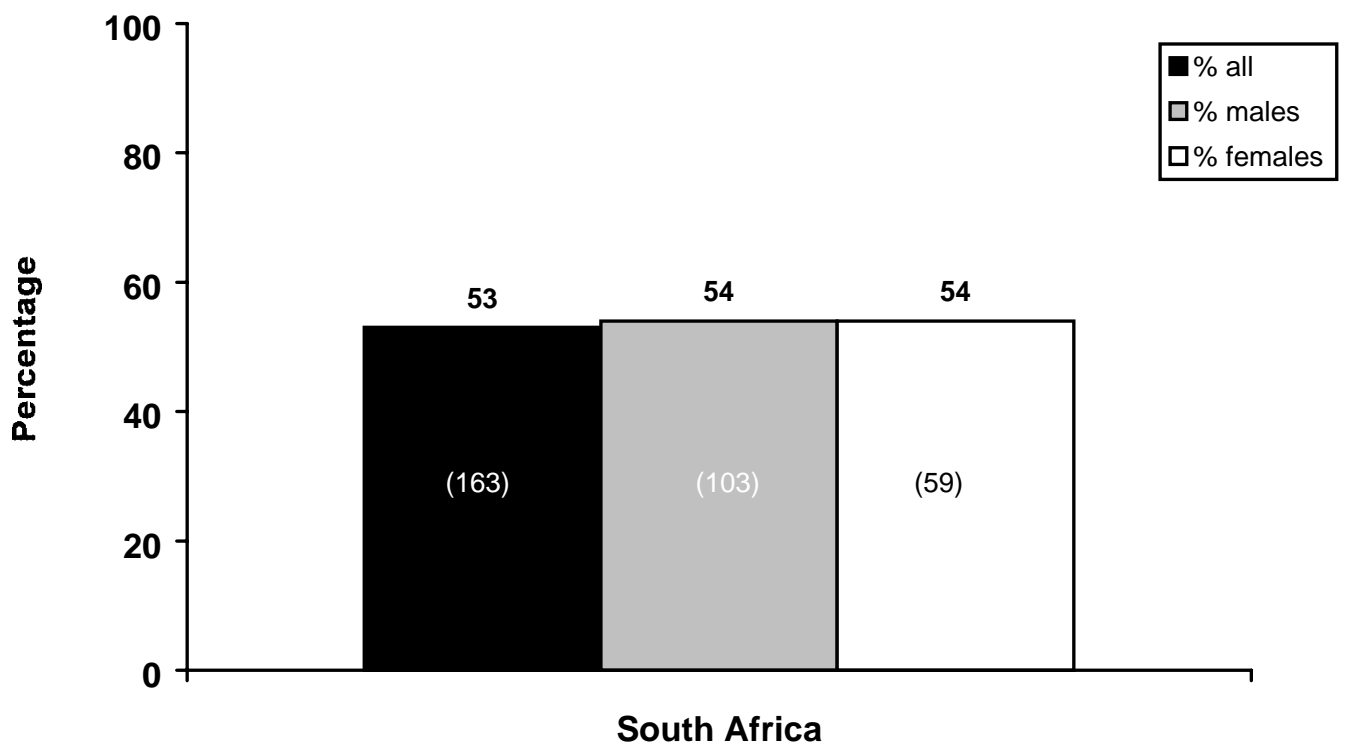




\section{Conclusions}

This report highlights a number of findings that have implications for school-based programs in the three research sites and elsewhere.

- Teachers need to be prepared for students with a range of sexual experiences, including forced sex. These studies found that in every site there are some young people who have sex at early ages suggesting that sex at such a vulnerable age may be forced or coerced. Where possible, referral systems to counselors and social workers need to be in place. In addition teachers need to know that some of the students are already sexually active and need information on adopting safe behaviors immediately. It is important to note that the majority of female students are not having sex, most females and many males in these studies have never had penetrative sex, and an even greater percentage had not had sex during the recall period. Working with these young people presents a real opportunity to prevent new HIV infections.

- Strategies for negotiating or refusing sex should take into account the intermittent nature of adolescent sex. Many students are not having sex regularly. This reality may affect the ways in which students prepare for and negotiate sexual encounters. Classroom discussions and exercises can identify the situations in which youth have sex, as well as barriers and strategies to adopting safe behavior.

- Courses should examine peer pressure. School courses can help young people to identify misperceptions that put pressure on them to have sex. An examination of assumptions and norms about sex-including norms about masculinity, femininity, and self-esteem-can prepare students to decide for themselves. Reinforcing positive perceptions about youth behavior can strengthen such behavior.

- Programs need to teach students to accurately assess their personal risk of HIV infection. Teachers and counselors need to teach students to assess their own risk by being able to identify the behaviors or circumstances that put them at risk.

- Teachers and curricula planners need to know that students know some things about HIV but that they also misunderstand or are unaware of other aspects of HIV. Teachers often say that students already know everything about HIV and sex, and students may think so as well. Yet their understanding appears to be uneven. Past research has already shown that school programs are able to improve students' knowledge about HIV/AIDS.

- Programs need to talk about PLHA. School programs can be a venue for reducing the stigma attached to HIV/AIDS. Interactive teaching methods can help students face some of the situations in which they are unsure how to act with people who have HIV. 


\section{${ }^{H} \boldsymbol{K}^{\text {rizons }}$}

- Programs need to address condom use. For young people to adopt safe sex practices, they need to feel confident about using condoms correctly. Because this is a difficult subject to address in a classroom, teachers need special preparation and help in discussing condom use and other intimate matters with students. The sensitive nature of some information in the life skills courses requires forethought and planning by program designers.

The researchers in Mexico, South Africa, and Thailand are currently analyzing the data from the post-intervention student surveys. By mid 2002 they will have looked at program impact and will be able to report on post-intervention changes in students' knowledge, attitudes, intentions and behavior. This analysis will further assist programmers to identify both student needs and the strengths and limits of school-based HIV prevention programs. 


\section{References}

Abt Associates Inc. 2000. The Impending Catastrophe: A Resource Book on the Emerging HIV/AIDS Epidemic in South Africa. Abt Associates South Africa Inc.

Alan Guttmacher Institute. 1994. Sex and America's Teenagers. New York/Washington DC: The Guttmacher Institute, 19-29.

Cáceres, C.F. et al. 1994. "Evaluating a school-based intervention for STD/AIDS prevention in Peru." Journal of Adolescent Health. 15(7): 582-591.

Fitzgerald, A.M. 1999. "Use of Western-Based HIV Risk-Reduction Interventions Targeting Adolescents in an African Setting." Journal of Adolescent Health, 25:52-61.

Grunseit, Anne. 1997. Impact of HIV and sexual health education on the sexual behavior of young people: a review update. UNAIDS 97.4 :

http://www.unaids.org/publications/documents/children/schools/grunskme.pdf

Havanon, Napaporn. 1996. "Talking to men and women about their sexual relationships: insights from a Thai study” in Zeidenstein, Sondra and Kirsten Moore, eds. Learning about Sexuality. New York: Population Council/ International Women's Health Coalition.

Kirby, Douglas. 1997. No Easy Answers. Washington, D.C.: The National Campaign to Prevent Teen Pregnancy.

— 1999. "Reducing teen pregnancy: Approaches that work." Contemporary Pediatrics January 8394.

National Department of Health of South Africa, MACRO International Inc., and Medical Research Council of South Africa. 1998. South Africa Demographic and Health Survey, Preliminary Report. Cape Town, South Africa.

Pick de Weiss, S. et al. 1990. Estudio psicosocial comparativo de varones que han y que no han embarazado a una adolescente [comparative psychosocial study of men who have and have not impregnated an adolescent.] Report presented at the Pan-American Health Organization, Washington, D.C.

Richter, L. and J. Swart-Kruger. 1995. “AIDS-Risk Among Street Children and Youth: Implications for Intervention," South African Journal of Psychology, 25(1): 31-38.

Rutenberg, Naomi et al. 2001. Transitions to Adulthood in the Context of AIDS in South Africa. Horizons-funded report of Wave 1. Washington, DC: Horizons.

Stanton, B.F. et al. 1998. "Increased protected sex and abstinence among Namibian youth following a HIV risk-reduction intervention: a randomized, longitudinal study," AIDS, 12:24732480 .

Secretaría de Salud (SSA). 1999. Principales Causas de Mortalidad en Población de 25 a 34 años Estados Unidos Mexicanos, 1999. http://www.ssa.gob.mx 


\section{Hgrizons}

Stewart, Holley and Abigail Harrison, 2000. Who Goes to School? An Analysis of Secondary School Records for Planning and Implementation of a School-based Risk Reduction Intervention. Presented at the $6^{\text {th }}$ National Conference on Reproductive Health Priorities, Cape Town, South Africa, August 2000 from findings from the Wellcome Trust funded study in Kwa Zulu Natal, South Africa: Understanding the context of adolescent sexual risk: a feasibility study to develop an intervention trial of school-based peer education.

Turner, C.F. et al. 1998. "Adolescent sexual behavior, drug use, and violence: increased reporting with computer survey technology," Science 280:867-871. May.

UNAIDS. 2000. Report on the global HIV/AIDS epidemic. Geneva, Switzerland. Joint United Nations Programme on HIV/AIDS.

UNAIDS/WHO. 2000. Epidemiological Fact Sheet Update

http://www.unaids.org/hivaidsinfo/statistics/june00/fact_sheets/pdfs/mexico.pdf 


\section{Hqrizons}

Horizons is a global operations research program designed to:

Cdentify and test potential str ategies to impro ve HIV/AIDS prevention, care, and suppor $\quad t$ programs and service delivery.

Oisseminate best pr actices and utilize findings with a vie w toward scaling up successful inter ventions.

For more information, please contact:

Horizons Program, Communications Unit 4301 Connecticut Avenue, NW Suite 280 Washington, DC 20008 USA

Tel: 202-237-9400

Fax: 202-237-8410

Email: horizons@pcdc.org www.popcouncil.org/horizons/horizons.html

\section{QP Population Council}

Horizons is implemented by the Population Council in collaboration with - International Center fr Researb on Women (ICPN)

· International HIV/AIDS Alliance

- Program fr Appropriate Tedhnology in Health (PATH)

- The University of Alabama at Birmingham

- Tulane University

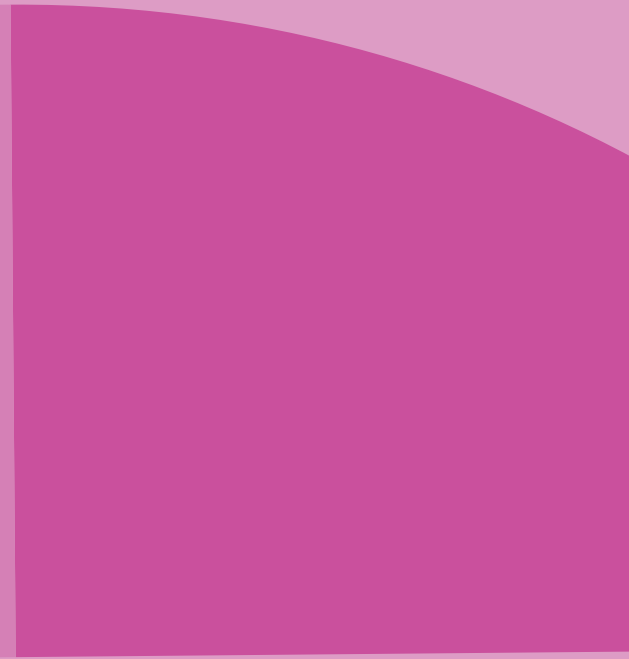

